\title{
Personal health and fitness in the curriculum of physical education at the primary level with increasing rates of childhood obesity \\ ${ }^{1}$ D. Ibrahim Abdelrazek Ahmed Selim \\ ${ }^{2}$ D. Ahmed Ibrahim Ahmed Azab \\ ${ }^{3}$ D. AbdulfattahRagabMatar
}

\section{Introduction:}

Obesity rates have spread among children till it has reached a global phenomenon according to the classification of World Health Organization. This increase is not limited to the developing countries, but it also involves many of the countries that are in the process of growth (3: 437) including the majority of Arab countries such asTunisia, Yemen, Bahrain, Kuwait, Morocco, Qatar, Egypt (15:41). Saudi Arabia, (18: 570). Jordan (17: 132).

The danger of obesity at such a young age lies in the fact that it is associated with many probable health risks like heart disease, blood vessels, digestive system, high blood pressure, increased blood cholesterol, diabetes mellitus

type 2, and several psychological and social problems (7: 266).Obesity in adulthood is likely to increase steadily the more when the more the child is obese after the age of three year regardless of his parents being obese or not. Whereas the prospects for a child to remain obese in adulthood exceed $50 \%$ in the case of obese children at childhood, this ratio does not exceed $10 \%$ even if a child was not obese at a younger age (12: 373 ).

In America, statistics indicates also that diseases associated with lack of movement causes the death of the equivalent of 14 times more than the deaths caused by $\operatorname{AIDS}(23: \quad 133)$.about 1,000 deaths per day happen due to

${ }^{1}$ Associate Professor of Movement Education in Faculty of Education - Taif University, Faculty of Physical Education - University of Sadat.

${ }^{2}$ Associate Professor in Department of Water Competitions and Sports in Faculty of Physical Education - University of Sadat.

${ }^{3}$ Associate Professor in Department of Special Education - University of Taif Faculty of Education - University of al-Azhar Assiut Journal For Sport Science Arts 
obesity, that obesity reduces human lifespan by about 2-5 years(25: 177, 399). About 35 $\%$ of deaths caused by heart disease, diabetes, and arteries and $32 \%$ of colon cancer deaths are attributed to physical inactivity which is considered one of the causes and symptoms of obesity (12: 373). The cost of obesity treatment and its associated diseases is about 150 billion dollars annually because there are about 63 million visits to doctors because of obesity (13: 145).

In Scotland, the costs of health care related to obesity are about 500 million pounds per year, and it costs the wider economy about 2 billion pounds (3: 437). In Saudi Arabia, is the deaths caused by obesity and its complications are about 20,000 deaths a year, and the annual cost of treating obesity and its complications of all ages is about 19 billion Saudi Riyals (15:45).

In spite of the various factors that cause obesity among children, (34: 11), (9: 324). the contemporary lifestyle which encourages inactivity and lack of physical effort remains one of the main causes of obesity among children (15:44). Thus a wide debate arises in the educational community about the feasibility of physical education school curricula. Paying attention to personal health and fitness is on top of this debate's list of goals. In life, one notices a low health behavior, increasing rates of inactivity and obesity among children in schools, and what results in serious health consequences and several psychological and social problems.

Several studies have been conducted in this respect including two studies. First, the results of the study conducted by "Abdul-Aziz Abdul-Karim and Abdul-Latif Ibrahim" (2002) (2) showed that the curriculum of physical education at the primary school does not achieve its objectives. Second, the results of study conducted by "Samir Abo Shadi and Ahmad AbdulSalam"(2010)(30) confirmed the low level of health behavior and activeness among primary school students.

Considering the practical fact of school physical education, we find that it only focuses on teaching students the skills connected 
with sporting activities, having them compete in order to reach the best performance of these skills, and forcing students to perform a set of regular exercises. However, none of these two goals managed to prepare a generation of healthy and sports. What is worse than this is that ex-athletes who are the most skilled ones among people are prone to obesity, heart disease, and blood vessels just like their non-athlete peers are $(28: 41,42)$.

From this point, there appears an important problem closely linked to the contents of personal health and fitness in the school curricula of physical education. Numbers and statistics confirm that they do not qualify children for the acquisition of personal health and fitness and do not help in the prevention of obesity or prepare them as adults able to lead their lifestyle later on actively and vigorously. Even students in physical education colleges and departments are not qualified to do so. Thus, this issue requires to develop these contents in order to upgrade and improve personal health and increase activity among children in schools which will reduce obesity rates among them.

The challenges facing physical education in schools "global" ones, and they apply to a great extent on all the countries of the world including Western countries even the United States of America. There are many studies and researches that touched on the development of school physical education in order to promote healthy lifestyles at an early age and reduce obesity rates among children. These studies have put forward some visions and solutions, for example:

- Quinn's study (2012) (29) calls for the need to take advantage of children's love of video games by incorporating them in the school curricula of physical education in the form of exciting games that encourage children to interact and participate in physical activities inside and outside theschool.

- Fernandez \& Sturm's study (2011) (11) emphasizes the need for providing adequate and quality equipment, facilities, and the tools required for physical activity in schools which provides greater opportunities 
for physical activity even after school. As a result, this will reduce obesity rates among children.

- Study by Bronson et al.(2011) (3) calls for legislating laws related to promoting physical activity and providing a suitable environment for activity including playgrounds, tools, approaches, and even sidewalks for students to walk on to school instead of riding a car.

- Woolford's

study(2011)(34)calls for the need to focus on behavioral therapy through guiding obese children in order to boost their self-confidence and modify their misconceptions about nutrition, and health and social behaviors, and doing sport.

- An article by Prusak et al. (2011)(28) entitled: A Critical Look at physical education and what should be done to deal with health in general and obesity in particular. The writers of the article suggest that physical education should focus on improving health and health preventive behaviors and meeting students' dynamic needs instead of focusing solely on teaching dynamic skills.

On this basis, this study seeks to identify the reality of personal health and fitness in the curricula of physical education at primary schools in Saudi Arabia in order to diagnose their current situation and compare it with the desired image set by health and fitness standards hoping to establish new contents that meet children's fitness and health needs, provide them all without exception - with necessary expertise about health and fitness to make them reach a high point of vigor, and reduce obesity rates among them.

\section{Research Objectives:}

1. Identifying the determinants of personal health and fitness which should be available in physical education curricular at primary schools in Saudi Arabia.

2. Identifying the availability of the determinants of personal health and fitness in physical education curricular at primary schools in Saudi Arabia.

\section{Methods and Procedures:}

First: The Sample:

A sample was selected randomly consisting of (500) 
physical education teachers at elementary schools from several cities representing different regions of Saudi Arabia (Jeddah, Najran, alQassim, Taif, al-Jawf, and Medina), provided that the teacher should be educationally qualified, a graduate from teachers' colleges or physical education departments in the faculties of education, and have no less than ten-yeasr experience in teaching physical education at primary schools.

Second: Study Tool:

- A form of building standards related to personal health and fitness in physical education curricular atprimary schools:

Reference to specialized references and related studies (16), (10), (2), (21), (24), (4), (5), (6), (14), (19), (20), (31), (26), (33), two main standards have been identified for questionnaire:

1. Students evaluate and maintain a level of fitness to improve health and performance.

2. Students demonstrate knowledge of fitness concepts, principles, and strategies to improve healthand performance.
Indicators of health and fitness suitable for each standard and class separately have been formulated, and in front of each phrase, there are four assessment indicators to express their availability in the curriculum (significantly, moderately, barely, none). Then the questionnaire was shown, in its initial form, to specialized experts in Saudi universities; after omitting, adding, and modifying, the questionnaire consists of (145) phrases and is ready to calculate scientific account coefficient.

\section{Validity of measures:}

Researchers

have

calculated the validity of internal consistency by applying the questionnaire to a sample, from the research community and outside the basic sample, that consisted of (60) physical education teachers at elementary schools. This is to recognize the representation of the questionnaire phrases for its key standards and how each entity is related to the standard's total degree. Tables $(1,2,3)$ illustrates that.

Table (1) 
The correlation coefficient between the degree of each entity and the standard's total degree to which it belongs in the questionnaireof personal health and fitness determinants in Movement Education curricula for first, second, and third grades $\mathbf{N}=\mathbf{6 0}$

\begin{tabular}{|c|c|c|c|c|c|c|c|c|c|c|c|}
\hline \multicolumn{4}{|c|}{ First Grade } & \multicolumn{4}{|c|}{ Second Grade } & \multicolumn{4}{|c|}{ Third Grade } \\
\hline \multicolumn{2}{|c|}{$\begin{array}{c}\text { First } \\
\text { Standard }\end{array}$} & \multicolumn{2}{|c|}{$\begin{array}{c}\text { Second } \\
\text { Standard }\end{array}$} & \multicolumn{2}{|c|}{$\begin{array}{c}\text { First } \\
\text { Standard }\end{array}$} & \multicolumn{2}{|c|}{$\begin{array}{c}\text { Second } \\
\text { Standard }\end{array}$} & \multicolumn{2}{|c|}{$\begin{array}{c}\text { First } \\
\text { Standard }\end{array}$} & \multicolumn{2}{|c|}{$\begin{array}{c}\text { Second } \\
\text { Standard }\end{array}$} \\
\hline $\begin{array}{l}\text { Entit } \\
\text { y No. }\end{array}$ & $\mathbf{R}$ & $\begin{array}{l}\text { Entit } \\
\text { y No. }\end{array}$ & $\mathbf{R}$ & $\begin{array}{l}\text { Entit } \\
\text { y No. }\end{array}$ & $\mathbf{R}$ & $\begin{array}{l}\text { Entit } \\
\text { y No. }\end{array}$ & $\mathbf{R}$ & $\begin{array}{l}\text { Entit } \\
\text { y No. }\end{array}$ & $\mathbf{R}$ & $\begin{array}{l}\text { Entit } \\
\text { y No. }\end{array}$ & $\mathbf{R}$ \\
\hline $1 / 1$ & 0,422 & $2 / 1$ & 0,541 & $1 / 1$ & 0,452 & $2 / 1$ & 0,324 & $1 / 1$ & 0,220 & $2 / 1$ & 0,522 \\
\hline $1 / 2$ & 0,358 & $2 / 2$ & 0,176 & $1 / 2$ & 0,432 & $2 / 2$ & 0,344 & $1 / 2$ & 0,505 & $2 / 2$ & 0,543 \\
\hline $1 / 3$ & 0,495 & $2 / 3$ & 0,443 & $1 / 3$ & 0,395 & $2 / 3$ & 0,394 & $1 / 3$ & 0,376 & $2 / 3$ & 0,591 \\
\hline $1 / 4$ & 0,445 & $2 / 4$ & 0,593 & $1 / 4$ & 0,477 & $2 / 4$ & 0,508 & $1 / 4$ & 0,405 & $2 / 4$ & 0,652 \\
\hline $1 / 5$ & 0,508 & $2 / 5$ & 0,496 & $1 / 5$ & 0,237 & $2 / 5$ & 0,613 & $1 / 5$ & 0,461 & $2 / 5$ & 0,324 \\
\hline $1 / 6$ & 0,552 & $2 / 6$ & 0,370 & $1 / 6$ & 0,173 & $2 / 6$ & 0,321 & $1 / 6$ & 0,400 & $2 / 6$ & 0,487 \\
\hline $1 / 7$ & 0,554 & $2 / 7$ & 0,426 & $1 / 7$ & 0,457 & $2 / 7$ & 0,435 & $1 / 7$ & 0,153 & $2 / 7$ & 0,680 \\
\hline $1 / 8$ & 0,634 & $2 / 8$ & 0,626 & $1 / 8$ & 0,521 & $2 / 8$ & 0,656 & $1 / 8$ & 0,615 & $2 / 8$ & 0,516 \\
\hline \multirow[t]{8}{*}{$1 / 9$} & 0,755 & $2 / 9$ & 0,449 & $1 / 9$ & 0,621 & $2 / 9$ & 0,502 & $1 / 9$ & 0,508 & $2 / 9$ & 0,496 \\
\hline & & $2 / 10$ & 0,386 & $1 / 10$ & 0,207 & $2 / 10$ & 0,293 & $1 / 10$ & 0,219 & $2 / 10$ & 0,344 \\
\hline & & $2 / 11$ & $\begin{array}{c}0,119 \\
-\end{array}$ & & & $2 / 11$ & 0,532 & $1 / 11$ & 0,114 & $2 / 11$ & 0,438 \\
\hline & & $2 / 12$ & 0,265 & & & $2 / 12$ & 0,418 & & & $2 / 12$ & 0,598 \\
\hline & & $2 / 13$ & 0,643 & & & $2 / 13$ & 0,435 & & & $2 / 13$ & 0,625 \\
\hline & & $2 / 14$ & 0,215 & & & $2 / 14$ & 0,388 & & & $2 / 14$ & 0,551 \\
\hline & & $2 / 15$ & 0,543 & & & 2/15 & 0,361 & & & $2 / 15$ & 0,369 \\
\hline & & & & & & & & & & $2 / 16$ & 0,334 \\
\hline
\end{tabular}

The table value of "P" is at (0.05) $=\mathbf{0 . 2 5 4}$
from Table (1), it is evident that the entities of first, second and third grade standards have correlation coefficients are statistically indicative at $(0.05)$ with the standard's total degree

to which it belongs except entities with the numbers $(2-2$, $2 / 11,2 / 14)$ for first grade, $(1 / 5$, $1 / 6,1 / 10)$ for second, and $(1 / 7$, $1 / 10,1 / 11)$ for third grade. 
Therefore, they have been omitted.

Table (2)

The correlation coefficient between the degree of each entity and the standard's total degree to which it belongs in the questionnaire of personal health and fitness determinants in Movement Education curricula for fourth, fifth, and sixth grades. $N=60$

\begin{tabular}{|c|c|c|c|c|c|c|c|c|c|c|c|}
\hline \multicolumn{4}{|c|}{ Fourth Grade } & \multicolumn{4}{|c|}{ Fifth Grade } & \multicolumn{4}{|c|}{ Sixth Grade } \\
\hline \multicolumn{2}{|c|}{$\begin{array}{c}\text { First } \\
\text { Standard } \\
\end{array}$} & \multicolumn{2}{|c|}{$\begin{array}{c}\text { Second } \\
\text { Standard }\end{array}$} & \multicolumn{2}{|c|}{$\begin{array}{c}\text { First } \\
\text { Standard }\end{array}$} & \multicolumn{2}{|c|}{$\begin{array}{c}\text { Second } \\
\text { Standard } \\
\end{array}$} & \multicolumn{2}{|c|}{$\begin{array}{c}\text { First } \\
\text { Standard }\end{array}$} & \multicolumn{2}{|c|}{$\begin{array}{c}\text { Second } \\
\text { Standard }\end{array}$} \\
\hline $\begin{array}{l}\text { Entit } \\
\text { y No. }\end{array}$ & $\mathbf{R}$ & $\begin{array}{c}\text { Entity } \\
\text { No. }\end{array}$ & $\mathbf{R}$ & $\begin{array}{l}\text { Entit } \\
\text { y No. }\end{array}$ & $\mathbf{R}$ & $\begin{array}{l}\text { Entit } \\
\text { y No. }\end{array}$ & $\mathbf{R}$ & $\begin{array}{c}\text { Enti } \\
\text { ty } \\
\text { No. } \\
\end{array}$ & $\mathbf{R}$ & $\begin{array}{l}\text { Entit } \\
\text { y No. }\end{array}$ & $\mathbf{R}$ \\
\hline $1 / 1$ & וד. ודי. & $2 / 1$ &..$\leqslant \leqslant T$ & $1 / 1$ & $.7 \leq 0$ & $2 / 1$ & $.0 \vee 9$ & $1 / 1$ & .019 & $2 / 1$ & $.0 \leqslant 1$ \\
\hline $1 / 2$ &.$r v q$ & $2 / 2$ & . r r & $1 / 2$ &.$\leqslant 91$ & $2 / 2$ & سq r. & $1 / 2$ & $.7 \leq \leqslant$ & $2 / 2$ & . \\
\hline $1 / 3$ & q & $2 / 3$ &.$\leqslant 1$. & $1 / 3$ &.$\leqslant 7 \pi$ & $2 / 3$ &..$\leqslant \leqslant 0$ & $1 / 3$ & ס $1{ }^{\prime}$ & $2 / 3$ & $\cdot .7 \leq 7$ \\
\hline $1 / 4$ & $\because v \cdot v$ & $2 / 4$ & $\cdot \leq 91$ & $1 / 4$ & $.7 r$. & $2 / 4$ & $.0 \leqslant$. & $1 / 4$ &.$r q$. & $2 / 4$ & . \\
\hline $1 / 5$ & $.70 r$ & $2 / 5$ & $.0 \wedge \wedge$ & $1 / 5$ &. .570 & $2 / 5$ & .071 & $1 / 5$ &.$\vee \vee \wedge$ & $2 / 5$ & $\cdot Y \cdot V$ \\
\hline $1 / 6$ & $.0 Y 1$ & $2 / 6$ & - r999 & $1 / 6$ & $\because \leqslant 1 \wedge$ & $2 / 6$ & • דז. & $1 / 6$ &.$r q 9$ & $2 / 6$ & oro \\
\hline $1 / 7$ & $.7 \leq Y$ & $2 / 7$ & דצr. & $1 / 7$ & .740 & $2 / 7$ & ו ו & $1 / 7$ &.$Y 19$ & $2 / 7$ & $\cdot r \leqslant 0$ \\
\hline $1 / 8$ & דוצח. & $2 / 8$ & - . $\leqslant 9 r$ & $1 / 8$ & $.07 \varepsilon$ & $2 / 8$ & س & $1 / 8$ & $.1 \wedge \wedge$ & $2 / 8$ &..$O Y Y$ \\
\hline \multirow[t]{9}{*}{$1 / 9$} &.$\leqslant r_{0}$ & $2 / 9$ & $\cdot . \leqslant O Y$ & $1 / 9$ &..$\leqslant \leqslant 1$ & $2 / 9$ & . rov & $1 / 9$ & .794 & & \\
\hline & & $2 / 10$ & ש ז r & & & $2 / 10$ & .rq. & & & & \\
\hline & & $2 / 11$ & $\cdot . \leqslant \Lambda$ & & & $2 / 11$ & $\cdot \leq \leqslant 7$ & & & & \\
\hline & & $2 / 12$ & $\cdot \Sigma v$. & & & $2 / 12$ &.$r 90$ & & & & \\
\hline & & $2 / 13$ & $.0 \cdot 1$ & & & $2 / 13$ & $.0 \times 9$ & & & & \\
\hline & & $2 / 14$ & $\cdot \Xi \backslash V$ & & & $2 / 14$ & $\cdot \Sigma 9 \vee$ & & & & \\
\hline & & $2 / 15$ & $\cdot r V r$ & & & $2 / 15$ & $\cdot r \vee q$ & & & & \\
\hline & & $2 / 16$ & . & & & $2 / 16$ & .119 & & & & \\
\hline & & $2 / 17$ & $\cdot .571$ & & & $2 / 17$ & $\cdot \leq \varepsilon$. & & & & \\
\hline
\end{tabular}

\section{The table value of " $P$ " is at $(0.05)=0.254$}

From Table (2), it is evident that the entities of fourth, fifth and sixth grade standards have correlation coefficients are statistically indicative at (0.05) with the standard's total degree 
to which it belongs except the entity with number $(2 / 16)$ for fifth grade and numbers $(1 / 3$, $1 / 7,1 / 8,2 / 5)$ for sixth grade. Therefore, they have been omitted.

Reliability:
The half split equation for Cronbach's alpha coefficient has been applied with SPSS program on the same previous sample on which was calculated. Tables illustrate that.

Table (3)

Alpha coefficient for the reliability of the questionnaire of personal health and fitness determinants in Movement Education curricula for first, second, and third grades $N=60$

\begin{tabular}{|c|c|c|c|c|c|c|c|}
\hline \multirow{2}{*}{ Grade } & \multirow{2}{*}{$\begin{array}{l}\text { Reliability } \\
\text { Coefficient }\end{array}$} & \multicolumn{2}{|c|}{ Odd Phrases } & \multicolumn{2}{|c|}{ Even Phrases } & \multirow{2}{*}{$\begin{array}{r}\text { Even } \\
\text { Phrases } \\
\end{array}$} & \multirow{2}{*}{$\begin{array}{c}\text { Alpha } \\
\text { Coefficient }\end{array}$} \\
\hline & & M.A. & Std. & M.A. & Std. & & \\
\hline \multirow{2}{*}{ irst } & First & $1 . .0$. & $r .19 V$ & $9 . \mathrm{YTV}$ & $r .1 V \lambda$ & $* . \leqslant \vee 7$ & $\cdot .774$ \\
\hline & cond & $11.71 \mathrm{~V}$ & r.vi. & Ir.MV & r.Ar. & $* . . \leqslant \vee 7$ & .70. \\
\hline \multirow{2}{*}{ Second } & First & $\Lambda .11 \mathrm{~V}$ & T.VTY & 1.ATV & $T . \leqslant \leq 7$ & $* ., Y \wedge \wedge$ & $\because \varepsilon 1$. \\
\hline & Second & 15.70. & $\varepsilon . \leqslant 71$ & $1 r .9 r 4$ & r.q. & $* .09 \mathrm{~V}$ &.$V I Y$ \\
\hline \multirow{2}{*}{ Third } & First & $9.9 \mathrm{~V}$ & $T . T \leqslant \Lambda$ & V.ATr & $r . \leqslant V \cdot$ & $* ., Y \wedge r$ &. $.01 Y$ \\
\hline & Second & س & $\leqslant .910$ & IT.TIV & $0.0 \pi$ & $* .707$ & $\cdot . \wedge .0$ \\
\hline
\end{tabular}

The table valueof " $P$ " at $0.05=0.254$

Table (4)

Alpha coefficient for the reliability of the questionnaire of personal health and fitness determinants in Movement Education curricula for fourth, fifth, and sixth grades. $N=60$

\begin{tabular}{|c|c|c|c|c|c|c|c|}
\hline \multirow{2}{*}{ Grade } & \multirow{2}{*}{\begin{tabular}{|l|} 
Reliability \\
Coefficient
\end{tabular}} & \multicolumn{2}{|c|}{ Odd Phrases } & \multicolumn{2}{|c|}{ Even Phrases } & \multirow{2}{*}{$\begin{array}{r}\text { Even } \\
\text { Phrases } \\
\end{array}$} & \multirow{2}{*}{$\begin{array}{c}\text { Alpha } \\
\text { Coefficient }\end{array}$} \\
\hline & & M.A. & Std. & M.A. & Std. & & \\
\hline \multirow{2}{*}{ Fourth } & First & V.VTV & T.M. I & $7.77 \mathrm{~V}$ & Y.OAY & $* . . \leqslant V \cdot$ &. $.77 T$ \\
\hline & Second & 10.TNH & 0.119 & $1 \varepsilon .+1 V$ & 5.111 & $* .0 \leqslant 7$ &.$V T r$ \\
\hline \multirow{2}{*}{ Fifth } & First & $1.07 \mathrm{~V}$ & $r .9 \wedge r$ & $0.91 \mathrm{~V}$ & T.TrT & $* .0 \leqslant \leqslant$ & .787 \\
\hline & Second & IE.9Tr & $\varepsilon .97 \varepsilon$ & $1 T . \leqslant 0$. & r.9人o & $* . . \Sigma 94$ &.$V Y T$ \\
\hline \multirow{2}{*}{ Sixth } & First & $\mathrm{V} . .$. & r.A99 & $0 . \leqslant 7 V$ & Y.IVE & $* . .49$ & $.0 . r$ \\
\hline & Second & 7. Yᄉ & T.YTO & 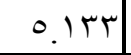 & $r . r \leq r$ & $* . . \varepsilon \cdot 7$ &.$r \wedge \Lambda$ \\
\hline
\end{tabular}

The table valueof " $P$ " at $0.05=0.254$

From tables $(3,4)$, it is evident indicative at (0.05). thus, the that the values of reliability form has consisted of (130) coefficients are statistically phrases after omitting (14) Assiut Journal For Sport Science Arts 
phrases and taken the final shape before applying it to the study sample.

According to the above mentioned, the first objective of the research has been achieved, namely, recognizing the determinants of personal health and fitness that should be incorporated in physical education curricula at primary schools in Saudi Arabia.

Third: The Application of the Questionnaire:

The questionnaire has been applied to a study sample of physical education teachers at primary schools in Saudi some cities. The sample consists of (500) teachers from

different cities from Monday corresponding to September 1st, 2014 to Thursday corresponding to September 25th 2014.

Result Presentation and Interpretation:

- In the Movement Education curriculum of first grade, there are Indicators of personal health and fitnessmoderately:

1. Participate in physical activities that are enjoyable and challenging.

2. Participate three to four times each week, for increasing periods of time, in moderate to vigorous physical activities that increase breathing and heart rate.

- In the Movement Education curriculum of first grade, there are indicators of personal health and fitness barely:

1. Demonstrate, for increasing periods of time, a "v" sit position, a push-up position with arms extended, and a squat position.

2. Move from a sitting to a standing position and from a lying to a sitting position without using arms to brace oneself while on the floor.

3. Sustain continuous movement for increasing periods of time while participating in moderate to vigorous physical activity.

4. Identify enjoyable and challenging physical activities that one can do for increasing periods of time without stopping.

- $\quad$ The following personal health and fitness indicators are not available in Movement Education curriculum for first grade:

1. Travel hand-over-hand along a horizontal ladder or hang from an overhead bar.

2. Stretch arms, shoulders, back, and legs without hyper 
flexing or hyper extending the joints.

3. Identify and use two indicators of increased capacity for vigorous physical activity to measure a change in activity levels.

4. Explain the importance of drinking water during and after physical activity.

5. Explain that nutritious food provides energy for alertness and mental concentration.

6. Recognize that the heart is the most important muscle in the body and is approximately the size of a fist.

7. Explain that increasing the heart rate during physical activity strengthens the heart muscle.

8. Identify physical activities that cause the heart to beat faster.

9. Describe the role of blood in transporting oxygen from the lungs.

10. Explain that strengthening muscles will help prevent injury and that strong muscles will produce more force.

11. Discuss how prolonged physical activity increases endurance, allowing movement to occur for longer periods of time.
12. Explain that the proper body position while stretching and strengthening will help prevent injury.

13. Diagram how flexible muscles allow more range of motion in physical activity.

14. Identify the body components (e.g., bones, muscles, organs, fat, and other tissues).

- Considering the indicators of personal health and fitness related to Movement Education curriculum for first grade, it is evident that:

- There are no indicators achieved by the curriculum significantly.

- The indicators achieved by the curriculum moderately have reached only indicators related to the fun and tough contents of physical activities and the number of weekly participations in physical activities.

$\circ$ The indicators achieved by the curriculum barely have reached (4) indicators related to moving from different positions for increasing periods and identifying difficult and fun physical activities.

- The indicators that are not available in the curriculum have reached (14) indicators 
related to muscular stamina activities, methods of evaluating physical activity, and functional information related to health and fitness such as the importance of drinking water, integrated food, body components like muscles, bones, systems, fat, tissues, and the role of the heart and lungs during

physical activityexercise.

\section{- In Movement}

Education curriculum for second grade, the following indicators of personal health and fitness are available moderately:

1. Participate in enjoyable and challenging physical activities for increasing periods of time.

2. Participate three to four times each week, for increasing periods of time, in moderate to vigorous physical activities that increase breathing and heart rate.

3. Perform abdominal curl-ups, modified push-ups, oblique curl-ups, forward and side lunges, squats, and triceps push-ups from a chair or bench to enhance endurance and increase muscle efficiency.

4. Engage in moderate to vigorous physical activity for increasing periodsof time.
- In Movement Education curriculum for second grade, the following indicators of personal health and fitness are not available:

1. Traverse the overhead ladder one bar at a time.

2. Demonstrate the proper form for stretching the hamstrings, quadriceps, shoulders, biceps, and triceps.

3. Measure improvements in individual fitness levels.

4. Explain the fuel requirements of the body during physical activity and inactivity.

5. Describe the role of moderate to vigorous physical activity in achieving or maintaining good health.

6. Identify ways to increase time for physical activity outside of school.

7. Discuss how body temperature and blood volume are maintained during physical activity when an adequate amount of water is consumed.

8. Explain how the intensity and duration of exercise, as well as nutritional choices, affect fuel use during physical activity.

9. Compare and contrast the function of the heart during rest and during physical activity. 
10. Describe the relationship between the heart and lungs during physical activity.

11. Compare and contrast changes in heart rate before, during, and after physical activity.

12. Describe how muscle strength and muscle endurance enhance motor skill performance.

13. Identify muscles being strengthened during the performance of particular physical activities.

14. Identify which activities or skills would be accomplished more efficiently with stronger muscles.

15. Explain the role that weight-bearing activities play in bone strength.

16. Identify the muscles being stretched during the performance of particular physical activities.

17. Explain why it is safer to stretch a warm muscle rather than a cold muscle.

18. Describe the differences in density and weight between bones, muscles, organs, and fat .

\section{- Considering the} indicators of personal health and fitness related to Movement Education curriculum for second grade, it is evident that:

- There are no indicators achieved by the curriculum significantly.

- The indicators achieved by the curriculum moderately have reached (2) indicators related to the participation in physical activities for long periods, the number of weekly participations in physical activities, and the power and stamina activities in order to achieve the desired level of fitness concerning health.

$\circ$ Lack of indicators achieved by the curriculum barely.

- The indicators that are not available in the curriculum have reached (18) related to flexibility exercises, measures of improving the level of individual fitness, and the functional information related to fitness which aims to improve health such as body requirements of energy, the role of food, the importance of drinking water to maintain body temperature, the relationship between the heart and lungs, the comparison between the heart rate before, during, and after physical activity, the role of physical activity in maintaining health,

Assiut Journal For Sport Science Arts 
ways to increase the time of physical activity outside school, the role of the musculature in dynamic performance, and the clarification of differences between muscles, bones, fat, systems, and organs.

- In the Movement Education curriculum of third grade, the following indicators of personal health and fitness are available significantly:

1. Demonstrate warm-up and cool-down exercises.

2. Hold for an increasing period of time basic stretches for hips, shoulders, hamstrings, quadriceps, triceps, biceps, back, and neck.

- In the Movement Education curriculum of third grade, the following indicators of personal health and fitness are available moderately:

1. Participate three to four days each week, for increasing periods of time, in continuous moderate to vigorous physical activities that require sustained movement of the large-muscle groups to increase breathing and heart rate.

2. Perform increasing numbers of each: abdominal curl-ups, oblique curl-ups on each side, modified push-ups or traditional push-ups with hands on a bench, forward lunges, side lunges, and triceps push-ups from a chair.

3. Sustain continuous movement for increasing periods of time while participating in moderate to vigorous physicalactivity.

- In the Movement Education curriculum for third grade, the following indicators of personal health and fitness are available barely:

1. Measure and record improvement in individual fitness activities.

2. Explain why a particular stretch is appropriate preparation for a particular physical activity.

- In the Movement Education curriculum for third grade, the following indicators of personal health and fitness are not available:

1. Climb a vertical pole or rope.

2. Demonstrate how to lift and carry objects correctly.

3. Identify the body's normal reactions to moderate to vigorous physical activity. 
4. List and define the components of physical fitness.

5. Explain the purpose of warming up before physical activity and cooling down after physical activity.

6. Recognize that the body will adapt to increased workloads.

7. Explain that fluid needs are linked to energy expenditure.

8. Discuss the need for oxygen and fuel to be available during ongoing muscle contraction so that heat and waste products are removed.

9. Describe the relationship between the heart, lungs, muscles, blood, and oxygen during physical activity.

10. Describe and record the changes in heart rate before, during, and after physical activity.

11. Explain that a stronger heart muscle can pump more blood with each beat.

12. Identify which muscles are used in performing muscular endurance activities.

13. Name and locate the major muscles of the body.
14. Describe and demonstrate how to relieve a muscle cramp.

15. Describe the role of muscle strength and proper lifting in the prevention of back injuries.

16. Identify flexibility exercises that are not safe for the joints and should be avoided.

17. Differentiate the body's ability to consume calories and burn fat during periods of inactivity and during long periods of moderate physical activity.

- Considering the indicators of personal health and fitness related to Movement Education curriculum for third grade in Saudi schools, it is evident that:

- The indicators available significantly in the curriculum have reached (2 indicators related to the clarification of warm-up and relaxation exercises and increasing the period of flexibility exercises.

- The indicators available moderately in the curriculum have reached (3) indicators related to the number of weekly participations in physical activities that require 
large muscles to act in order to increase the rate of breathing and heart rate, some hands and abdomen exercises which develop muscles, and strengthening these activities continually.

- The indicators available barely in the curriculum have reached only (2) indicators related to measuring the extent of improvement in individual fitness activities and illustrating the importance of flexibility exercises the warmup and preparation.

- Indicators that are not available in the curriculum have reached (17) indicators related to some power activities such as lifting things correctly, climbing a column or rope, and functional information related to the exercising physical activity like knowing fitness components, the importance of warm-up, adaptation to physical activity, body needs of fluids for generating energy, the importance of oxygen in muscle work, the relationship between heart, lungs, muscles, blood, and oxygen during physical activity, the changes occurring to the heart during physical activity, the names of major muscles and their role in the process of lifting correctly, muscular contraction and how get rid of it, unsafe flexibility exercises, and consuming calories during relaxation and physical activity.

- In the physical education curriculum for fourth grade, the following indicators of personal health and fitness are available significantly:

1. Participate in appropriate warm-up and cooldown exercises for particular physical activities.

2. Explain the purpose of warm-up and cooldownperiods.

- In the physical education curriculum for fourth grade, the following indicators of personal health and fitness are available moderately:

1. Participate three to four days each week, for increasing periods of time, in continuous moderate to vigorous physical activities at the appropriate intensity to increase aerobic capacity.

2. Perform increasing numbers of each: abdominal curl-ups, oblique curl-ups on each side, modified push-ups 
or traditional push-ups, and triceps push-ups.

3. Demonstrate basic stretches using proper alignment for hamstrings, quadriceps, hip flexors, triceps, back, shoulders, hip adductors, hip abductors, and calves.

4. Sustain continuous movement for increasing periods of time while participating in moderate to vigorous physical activity.

5. Identify the correct body alignment for performing lower-body stretches.

6. Explain the value of increased flexibility when participating in physical activity.

- In the physical education curriculum for fourth grade, the following indicators of personal health and fitness are available barely:

1. Hang by the hands from an overhead bar with the hips and knees each at a 90-degree angle.

2. Measure and record changes in aerobic capacity and muscular strength, using scientifically based healthrelated physical fitness assessments.
3. Meet minimum requirements for health-related physical fitness, using scientifically based healthrelated physical fitness assessments

4. Explain the principles of physical fitness: frequency, intensity, time, and type.

5. Describe the difference between muscular strength and muscular endurance.

- In the physical education curriculum for fourth grade, the following indicators of personal health and fitness are not available:

1. Demonstrate the correct body position for pushing and pulling large objects.

2. Set personal short-term goals for aerobic endurance, muscular strength and endurance, and flexibility and monitor progress by measuring and recording personal fitness scores.

3. Identify healthful choices for meals and snacks that help improve physical performance.

4. Explain why the body needs water before, during, and after physical activity.

5. Explain why the body uses a higher percentage of carbohydrates for fuel during 
high-intensity physical activity and a higher percentage of fat for fuel during low-intensity physical activity.

6. Calculate personal heart rate per minute by recording heartbeats for ten-second intervals and 15-second intervals.

7. Explain why a strong heart is able to return quickly to its resting rate after exertion.

8. Identify

two characteristics of physical activity that build aerobic capacity.

9. Determine the intensity of personal physical activity by using the concept of perceived exertion.

10. Explain why muscular endurance or muscular strength activities do not increase muscle mass in preadolescent children.

11. Recognize how strengthening major muscles can improve performance at work and play.

12. Describe the correct form to push and pull heavy objects.

13. Explain the effect of regular, sustained physical activity on the body's ability to consume calories and burn fat for energy.
- Considering the indicators of personal health and fitness related to physical education curriculum for fourth grade, it is evident that:

- The indicators achieved by the curriculum significantly have reached only indicators related to participation in appropriate warm-up and relaxation exercises according to the type of activity and clarification of their purpose.

- The indicators achieved by the curriculum moderately have reached (6) indicators related to the number of weekly participations which develops aerobic work, some abdominal and arm activities that develop muscular ability, key flexibility exercises and the importance of taking the right position when doing them, supporting continuous movement, and explaining the purpose from the warm-up and relaxation.

- The indicators achieved by the curriculum barely have reached (5) indicators related to assessing muscular stamina and on a scientific basis, clinging to a girder to increase strength, to meeting the minimum requirements of 
health-related fitness, explaining the principles of fitness (repetition, intensity, time, and type), and shows the difference between muscular strength and stamina.

- The indicators that are not available in the curriculum have reached (13) indicators related to the right position of the body when pushing or pulling large and heavy objects, setting short- term personal goals for some fitness elements and measuring how they improve, food aspects related to physical activity such as healthy meals, the importance of water, and the use of carbohydrates and fat to get energy, physiological aspects related to aerobic work like calculating heart rate per minute and how a strong heart returns more quickly to its normal state after activity, explaining why muscular strength and stamina activities do not increase in preadolescence, the role of the major strong muscles in improving the performance, and the impact of physical activity on consuming calories.

- In the physical education curriculum for fifth grade, the following indicators of personal health and fitness are available significantly:

1. Perform an increasing number of oblique curl-ups on each side.

- In the physical education curriculum for fifth grade, the following indicators of personal health and fitness are available moderately:

1. Demonstrate how to warm up muscles and joints before running, jumping,kicking, throwing, and striking.

2. Participate three to four days each week, for increasing periods of time, in continuous moderate to vigorous physical activities at the appropriate intensity to increase aerobic capacity.

3. Perform flexibility exercises that will stretch particular muscle areas for given physical activities.

4. Sustain continuous movement for an increasing period of time while participating in moderate to vigorous physical activities.

5. Explain the elements of warm-up and cool-down activities.

6. Explain the benefits of stretching after warm-up activities. 
- In the physical education curriculum for fifth grade, the following indicators of personal health and fitness are available barely:

1. Performing more lifting by using triceps.

2. Identifying the intensity of personal physical activity by using the concept of tangible effort (perceptible).

3. Explaining the benefits of a strong arm, chest, rear muscles.

- In the physical education curriculum for fifth grade, the following indicators of personal health and fitness are not available:

1. Plan a day of healthful balanced meals and snacks designed to enhance the performance of physical activities Assessment

2. Assess health-related physical fitness by using a scientifically based healthrelated fitness assessment.

3. Meet age- and genderspecific fitness standards for aerobic capacity, muscular strength, flexibility, and body composition, using a scientifically based healthrelated fitness assessment.

4. Record and analyze food consumption for one day and make a plan to replace foods with healthier choices and adjust quantities to enhance performance in physical activity.

5. Explain why

dehydration impairs

temperature regulation and physical and mental performance.

6. Develop and describe three short-term and three long-term fitness goals.

7. Examine personal results of a scientifically based healthrelated physical fitness assessment and identify one or more ways to improve performance in areas that do not meet minimum standards.

8. Record water intake before, during, and after physical activity.

9. Describe the principles of training and the application to each of the components of health-related physical fitness.

10. Identify the heart rate intensity (target heart-rate range) that is necessary to increase aerobic capacity.

11. Compare target heart rate and perceived exertion during physical activity.

12. Measure and record the heart rate before, during, and after vigorous physical activity. 
13. Explain how technology can assist in the pursuit of physical fitness.

14. Explain why body weight is maintained when calorie intake is equal to the calories expended.

15. Describe the short- and long-term benefits of maintaining body composition within the healthy fitnesszone.

- Considering the indicators of personal health and fitness related to physical education curriculum for fifth grade, it is evident that:

- The indicators achieved by the curriculum significantly have reached (1) indicator related to performing an increasing number of bending on each side.

- The indicators achieved by the curriculum moderately have reached (5) indicators related to the ways and benefits of warming up muscles and joints before the physical activity, elements of warm-up and relaxation, number of weekly participations to increase stamina, flexibility exercises for certain areas of the body, and supporting the continuous movement.

- The indicators achieved by the curriculum barely have reached (3) indicators related to the performing increasing numbers of lifting by using triceps, identifying personal physical activity intensity through observation, explaining the benefits of strong arms, chest, and rear muscles.

- The indicators that are not available in the curriculum have reached (15) indicators related to nutrition aspects associated with physical activity such as a one-day plan for a healthy meal consistent with body consumption during physical activity, water consumption before, during, and after physical activity, the seriousness of lack of water on physical performance and how the body maintains its weight when calorie intake is equal to the calories consumed, defining health-related fitness criteria, evaluating them scientifically, how to improve them, and the benefits of maintaining them, setting three short-term objectives and three long-term ones related to fitness, describing the principles of training and application of health-related fitness components, showing the heart rate necessary to increase stamina, comparing the heart rate with the 
perceptible effort during physical activity, measuring and recording heart rate during and after physical activity, and explaining the role of technology in helping practice physicalactivity.

- In the physical education curriculum for sixth grade, the following indicators of personal health and fitness are available moderately:

1. Participate in moderate to vigorous physical activity a minimum of four days each week.

2. Identify contraindicated exercises and their adverse effects on the body.

- In the physical education curriculum for sixth grade, the following indicators of personal health and fitness are available barely:

1. Measure and evaluate changes in health-related physical fitness based on physical activity patterns.

2. Distinguish between effective and ineffective warmup and cool-down techniques.

3. Classify physical activities as aerobic oranaerobic.
- In the physical education curriculum for sixth grade, the following indicators of personal health and fitness are not available:

1. Assess the components of health-related physical fitness (muscle strength, muscle endurance, flexibility, aerobic capacity, and body composition) by using a scientifically based healthrelated fitness assessment.

2. Compare individual physical fitness results with research-based standards for good health.

3. Develop individual goals for each of the components of health-related physical fitness (muscle strength, muscle endurance, flexibility, aerobic capacity, and body composition).

4. Monitor the intensity of one's heart rate during physical activity.

5. Develop a one-day personal physical fitness plan specifying the intensity, time, and types of physical activities for each component of healthrelated physical fitness.

6. Explain methods of monitoring heart rate intensity. 
7. List the long-term benefits of participation in regular physical activity.

8. Compile and analyze a log noting the food intake/calories consumed and energy expended through physical activity.

- Considering the indicators of personal health and fitness related to physical education curriculum at for sixth-grade, it is evident that:

- There are no indicators achieved by the curriculum significantly.

- The indicators achieved by the curriculum moderately have reached (2) indicators related to the number of participations in weekly physical activities and illustrating some harmful exercises and their effects on the body.

- The indicators achieved by the curriculum barely have reached (3) indicators related to evaluating the level of health-related fitness, illustrating effective and ineffective techniques of warm-up and relaxation, and classifying anaerobic and aerobic physical activities.

- The indicators that are not available in the curriculum have reached (8) indicators related to the evaluating of the level of health-related fitness through setting individual objectives for each element of fitness, evaluating the extent of improvement scientifically, and comparing this improvement with standards determined by scientific researches, making daily plans for students taking into account individual differences among them in terms of intensity, size, and comfort, and functional information related to the practicing physical activity such as knowing the physical activity benefits in the long run, how to calculate heart rate during physical activity, and controlling the amount of food, energy, and calories consumed.

According to the aforementioned, the second objective of the research has been achieved, namely, finding out the availability of personal health and fitness determinants in physical education curricula for primary schools inSaudi Arabia.

\section{Conclusions:}

1. The study has concluded to set personal health and fitness determinants in Movement Education curricula at Saudi schools from first to 
third grade and physical education curricula from fourth to sixth grade.

2. According to teachers, current curricula in dynamic and physical education for primary school students do not include personal health and fitness determinants.

\section{Recommendations:}

1. Reviewing the contents of personal health and fitness in physical education curricula for primary school students in Saudi Arabia.

2. Consulting the proposed criteria and indicators on approval of physical education curricula in primary schools in Saudi Arabia.

3. Circulating the proposed criteria and indicators for all primary schools by Ministry of Education, and assign teachers to apply them.

4. Suggesting other criteria for the rest of physical education curricula contents.

5. Paying attention to conduct assessment studies for the rest of physical education curricula in various educational stages.

\section{References:}

1. Abdul Aziz Abdul Karim, Abdul Latif Ibrahim (2002): Achieving the objectives of physical education curriculum at primary school in Saudi Arabia, a published research, Journal of Education Sciences, First Issue, Dar Qatar National Library.

2. Abdul Aziz al-Hakim Blatah (2008): an outlook of dynamic education programs for primary school students from the perspective of Physical Education technical guidance, Fourth Regional Conference of International Council for Health, Physical Education, Recreation, and Dynamic Expression for Middle East, Faculty of Physical Education for Boys, Alexandria University.

3. Brownso,R., Chriqui,J., Burgeson,C.,Fisher,M., \&Ness,R.(2011): Translating Epidemiology Into Policy to Prevent Childhood Obesity, The Case for Promoting Physical Activity in School Settings. Epidemiology and Policy to prevent obesity,20(6), 436-444.

4. California state board of education (2005): physical education model content standards for public schools : Kindergarten through grade twelve, U.S.A. 
5. Cawley,J.,

Frisvold,D.,\&Meyerhoefer,C.( 2013): The impact of physical education on obesity among elementary school children. Journal of Health Economics, 32(4), 743-755.

6. Connecticut

State

Department of Education Division of Teaching and Learning (1998): The Connecticut FrameworkK-12 Curricular Goals And Standards, Connecticut, USA.

7. Craigiea, A., Lakeb, A., Kellyc, S., Adamsond, A., \&Matherse, J.(2011): Tracking of obesity-related behaviours from childhood to adulthood, A systematic review. Maturitas,70,266- 284.

8. Douglas, O., (2010): Improving physical education in primary schools, a report by HM inspector ate of education. British medical journal, June, 22 (2), 137 - 151.

9. Dunton, G., Durand, P., Riggs, R., \&Pentz, M.(2011): Chapter $30 \quad$-School-Based Obesity-Prevention Programs. Arch PediatrAdolesc Med, 319-331

10. Eman Mohammad Rabei (2004): An analytical study of the objectives of physical education curricula at primary school in Arab Republic of Egypt, Master's Dissertation, Faculty of Physical Education, Tanta University.

11. Fernandes,M., \&Sturm,R. (2011): Facility provision in elementary schools, Correlates with physical education, recess, and obesity. Preventive Medicine,50,30-35.

12. Frisvold, D.,\& Lumeng, J.(2011): Expanding Exposure, Can Increasing the Daily Duration of Head Start Reduce Childhood Obesity? Journal of Human Resources, 46 (2),373402.

13. Gao,Z., Oh ,H., \&Sheng,H.(2011): $\quad$ Middle School Students' Body Mass Index and Physical Activity Levels in Physical activity levels in physical education. Research Quarterly for Exercise and Sport,82(1),145150.

14. Hawaii Department of education (1999): Physical Education Content Standards, Hawaii, USA.

15. Hazza' Mohammad alHazza' (2009): Today's young generation, less active and more obese, Third Arab Conference for Obesity and Physical Activity, Manama, 
Kingdom of Bahrain, January 19th -21 th.

\section{Ibrahim}

BassiouniOmaira, Fathi ElDeeb (1975): Teaching of Science and Scientific Education, Fifth Floor, Dar Elmaref, Cairo.

17. Ja'farFaress al-Arjan, Ghazi Mohammad al-Kilani (2012): indicators of structural growth and health-related fitness among Jordanian children between (7-15 years), the fifth International Scientific Conference: Sport Sciences in a Changing World, Faculty of Physical Education, University of Jordan, Amman, Jordan, pp. 131-157.

18. Mashaan bin Zabin elHarbi (2012): Level of healthrelated fitness and physical activity among students between 12-15 years in Riyadh. Journal of King Saud University - Educational Sciences and Islamic Studies, Saudi Arabia, Volume 24th, Second Issue, pp. 569-584.

19. Mcneil, M.,\&Boonsan, C., (2009): Moving towards quality physical education : physical education provision in singe pore, European physical education review, 15 (2), 201 223.
20. Michigan Department of education (1998): Physical education content standards and benchmarks, Michigan, U.S.A.

21. Mohammad Naji Abo Ghoneim (2010): The importance of bio-rhythm and use of certain aids for physical performance among children between (6-11 years) to reduce the risk of obesity, Thirteenth International Scientific Conference, "Physical

Education and Sport Challenges of Third Millennium ", Faculty of Physical Education for Boys, Helwan University, Third Volume, pp. 433-456.

22. Moussa Abbas (2008): An evaluative study of school sports under modern trends of development in the United Arab Emirates, Fourth Regional Conference of International Council for Health, Physical Education, Recreation, and Dynamic Expression for Middle East, Third Volume, Faculty of Physical Education for Boys, Alexandria University.

23. Murphey,

D., Mackintosh, B., \&McCoyRoth, M.(2011 ): Early Childhood Policy Focus, 
Healthy Eating and Physical Activity. Early Childhood Highlights. 2(3),133-140.

24. Mustafa Sayeh Mohammad, Abdul Basset Saddick (2008): Academic criteria proposed for the content of physical education curricula at primary school in light of education quality, Fourth Regional Conference of International Council for Health, Physical Education, Recreation, and Dynamic Expression for Middle East, First Volume, Faculty of Physical Education for Boys, Alexandria University.

25. Peterson, J., Puh,R., \&Luedicke,J.(2011): An experimental investigation of physical education teachers and coaches reactions to weightbased victimization in youth. Psychology of Sport and Exercise, 13,177-185.

26. Philip, J. M. (2008): Physical education in primary schools : classroom teachers perceptions of benefits and outcomes, health education journal , 67(3), 196 - 207

27. Phillips, E., Hull, E.,\&Rofey, L. (2011): Childhood Obesity Psychological Correlates and Recommended Therapeutic
Strategies. Health Education Research,14,399-410.

28. Prusak, K. ,Graser, S. V., Pennington, T., Zananderea, M., Wilkingson,C., \& Hager, R. (2011): A Critical Look at Physical Education and What Must Be Done to Address Obesity Lssues. Journal of physical educational, Recreation \& Dance, 5, 39-88.

29. Quinn, M.(2012): Introduction of Active Video Gaming Into the Middle School Curriculum as a School-based Childhood Obesity Intervention. Journal of Pediatric Health Care, 14(2), 22-35.

30. Samir Mohammad Abo Shadi, Ahmad Mohammad Abdul Salam (2010): Measuring the level of health behavior and orientation towards physical activity for students between 9-12 years at primary schools in Riyadh; Fifty-Second Conference of International Council for Health, Physical Education, Recreation, and Dynamic Expression, Qatar, pp. 201220.

31. Sanchez-Vaznaugh,E.V., Sánchez,B.N., Rosas,L.GJonggyu,R.L., \&Egerter,B.S.(2012):Physical 
Education Policy Compliance and

Children's Physical Fitness .A merican Journal of Preventive Medicine, 42(5),452-459.

32. SuhairBedier (1980): Curricula in Physical Education, Dar Elmaref, Cairo. 33. Vermont, S. (2004): Physical education content standards, benchmarks of education, U.S.A.

34. Woolford, S., Walker, R., Linton, M., Bakerson, A., \&Larrier, I., (2011):The Role of School Counselors in the Childhood Obesity Epidemic. Journal of School Counseling, 9(3), 1-33. 